\title{
Sutureless repair for postinfarction cardiac rupture: A simple approach with a tissue-adhering patch
}

\author{
Giuseppe M. Raffa, MD, Giuseppe Tarelli, MD, Davide Patrini, MD, and Fabrizio Settepani, MD, \\ Milano and Bergamo, Italy
}

Left ventricle free wall rupture (LVFWR) occurs in $2 \%$ to $4 \%$ of patients following acute myocardial infarction (AMI). ${ }^{1}$ Several techniques have been proposed to treat LVFWR, including sutures with pledgets, Dacron patch, and infartectomy, as well as the use of biologically glued autologous/heterologous pericardial or Teflon patches. ${ }^{1}$ TachoSil (Nycomed, Linz, Austria), a ready-to-use surgical patch, consists of a white collagen sponge coated on one side with fibrinogen and thrombin that allows hemostasis and tissue sealing, and is also used in cardiovascular surgical procedures. ${ }^{2}$ Since August 2008, 6 consecutive patients affected by LVFWR were treated using the TachoSil patch.

The mean interval between AMI and LVFWR, and LVFWR and operation was $5 \pm 3$ days and $3 \pm 2$ hours, respectively. Coronary angiography was not performed in 2 patients because of instability and 3 patients had undergone previous percutaneous myocardial revascularization.

All patients were operated on via a sternotomy. Myocardial infarction localized in the lateral cardiac wall was found in 2 patients, in the posterior and lateral cardiac

From the Department of Cardiac Surgery, Istituto Clinico Humanitas, Milano and Bergamo, Italy.

Disclosures: Authors have nothing to disclose with regard to commercial support. Received for publication July 29, 2012; revisions received July 29, 2012; accepted for publication Aug 21, 2012; available ahead of print Sept 24, 2012.

Address for reprints: Giuseppe M. Raffa, MD, Unit of Cardiac Surgery, Istituto Clinico Humanitas, Via Manzoni 56, cap: 20089, Rozzano (MI), Milano, Italy (E-mail: giuseppe.raffa78@gmail.com).

J Thorac Cardiovasc Surg 2013;145:598-9

$0022-5223 / \$ 36.00$

Copyright (C) 2013 by The American Association for Thoracic Surgery

http://dx.doi.org/10.1016/j.jtcvs.2012.08.049 wall in 2 cases, and in the posterior wall and cardiac apex in 1. One patient had isolated left ventricular apex involvement. According to LVFWR lesion classification, the "oozing" type ${ }^{1}$ was present in 4 patients whereas the "blow-out" type was present in 2 patients. A TachoSil patch was anchored and pressed with wet gauze to the dry surface of the ventricle for a few minutes. In 2 patients, a simple patch was not large enough to cover the entire damaged surface, so a second patch was used. Surrounding healthy myocardium not involved in the necrotic scar was also included in the TachoSil patch application in all patients to allow better anchoring and to avoid rerupture. Cardiopulmonary bypass (CPB) and cardiac arrest for an unstable hemodynamic condition, and to obtain a satisfactory exposure of the lateral and posterior cardiac wall, were necessary in 3 patients, whereas the beating-heart procedure was used in the remaining 3 patients. Mean CPB and aortic crossclamp time were $47 \pm 18$ minutes and $17 \pm 6$ minutes respectively. Mean operation time was $150 \pm 127$ minutes. No surgical revascularizations was performed. Operative data and postoperative complications are detailed in Table 1.

We had 1 death on postoperative day 6 that resulted from low cardiac output syndrome. A new blow-out type of LVFWR localized at the cardiac apex occurred on postoperative day 15 and was treated urgently with 3 Teflon-reinforced 4/0 polypropylene single stitches without CPB. All discharged patients are alive and have a good clinical status at a mean follow-up of $24 \pm 18$ months.

The introduction of sutureless techniques for LVFWR repair allowed a decrease in operative mortality rate from $24 \%$ to $35 \%$ to $15.6 \%$ to $0 \% .{ }^{1}$ The treatment of LVFWR

TABLE 1. Patients details, operative variables, and postoperative outcomes after TachoSil left ventricle free wall rupture repair

\begin{tabular}{|c|c|c|c|c|c|c|c|c|c|c|c|}
\hline $\begin{array}{l}\text { Patient } \\
\text { no. }\end{array}$ & Age, $y$ & Sex & $\begin{array}{l}\text { LVFWR } \\
\text { site }\end{array}$ & $\begin{array}{c}\text { LVFWR } \\
\text { type }\end{array}$ & $\begin{array}{c}\text { CPB } \\
\text { time, min }\end{array}$ & $\begin{array}{l}\text { AoClamp } \\
\text { time, min }\end{array}$ & $\begin{array}{l}\text { Operative } \\
\text { time, min }\end{array}$ & $\begin{array}{l}\text { ICU stay, } \\
\text { days }\end{array}$ & $\begin{array}{l}\text { Postoperative } \\
\text { complications }\end{array}$ & Outcome & $\begin{array}{c}\text { Follow-up, } \\
\text { mo }\end{array}$ \\
\hline 1 & 68 & M & Lateral wall & Oozing & - & - & 65 & 6 & $\begin{array}{l}\text { Dialysis, postoperative } \\
\text { AMI }\end{array}$ & Dead & - \\
\hline 2 & 78 & F & $\begin{array}{l}\text { Lateral and posterior } \\
\text { walls }\end{array}$ & Oozing & 38 & 13 & 153 & 7 & $\mathrm{ARF}, \mathrm{AF}$ & Alive & 43 \\
\hline 3 & 83 & $\mathrm{~F}$ & $\begin{array}{l}\text { Lateral and posterior } \\
\text { walls }\end{array}$ & Oozing & 35 & 14 & 165 & 11 & $\mathrm{ARF}, \mathrm{AF}$ & Alive & 42 \\
\hline 4 & 83 & F & Apex & Oozing & - & - & 62 & 5 & $\mathrm{AF}$ & Alive & 21 \\
\hline 5 & 68 & M & $\begin{array}{l}\text { Posterior wall } \\
\text { and apex }\end{array}$ & Blow-out & 68 & 25 & 392 & 9 & $\begin{array}{l}\mathrm{ARF}, \mathrm{AF} \text {, heart wall } \\
\text { rerupture }\end{array}$ & Alive & 12 \\
\hline 6 & 60 & M & Lateral wall & Blow-out & - & - & 63 & 2 & - & Alive & 3 \\
\hline
\end{tabular}

$L V F W R$, Left ventricle free wall rupture; $C P B$, cardiopulmonary bypass; AoClamp, aortic crossclamp; ICU, intensive care unit; $M$, male; $F$, female; $A M I$, acute myocardial infarction; $A R F$, acute renal failure; $A F$, atrial fibrillation. 


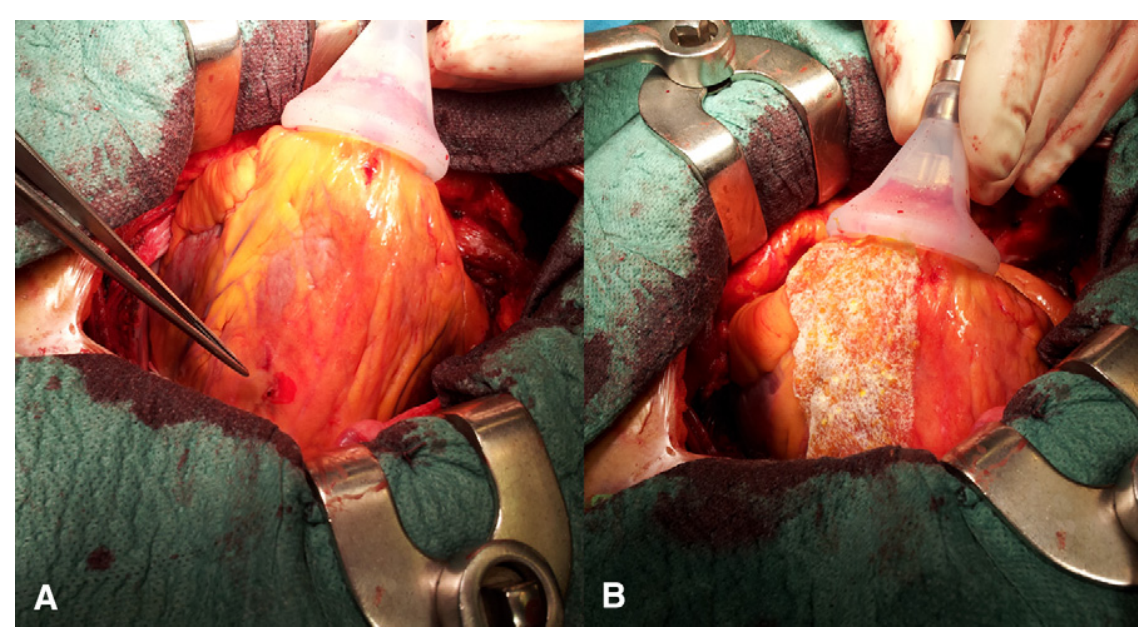

FIGURE 1. Operative findings of "blow-out" type left ventricle rupture in the lateral cardiac wall (A) repaired on a beating heart with apical suction devices (A, B). B, Two 9- $\times$ 4-cm patches of TachoSil (Nycomed, Linz, Austria) were positioned on the cardiac rupture, with complete bleeding control (Table 1 , patient 6).

using either the TachoComb or TachoSil patches, which are similar, has been noted in the literature. ${ }^{3,4}$ In 2005, Muto and colleagues ${ }^{3}$ reported a case of oozing-type LVFWR localized in the lateral wall, which as treated successfully off pump with this fibrin tissue adhesive. Recently, Pocar and associates ${ }^{4}$ treated 3 patients with LVFWR with the TachoSil patch and the addition of a second layer of pericardium to reinforce the rupture area during CPB. TachoComb use has been advocated by some authors ${ }^{1}$ before patch-andglue repair to prevent rerupture occurring from oozingtype ruptures.

We started using TachoSil to treat postinfarction cardiac rupture in 2008 and, to our knowledge, this is the first report of a series of 6 consecutive patients affected by LVFWR treated with this technique. The technique is easily reproducible and fast. Moreover, in 3 patients a beating heart procedure was used, and easy exposure of the lateral wall was achieved with an apical suction device in patient 6 (Table 1, Figure 1). Our results were satisfactory; the only death resulting from extensive AMI occurred in a patient with a poor preoperative clinical condition. One patient experienced a new rupture in an area not covered by the previous patch. He underwent an additional operation and both the softness of TachoSil and the surrounding fibrotic myocardium allowed us to suture the new rupture without complications.
In conclusion, surgical treatment of LVFWR should be expeditious and simple, and it should avoid suturing the friable infarcted ventricle. A sutureless technique can be used for LVFWR also without CPB. Since 2008, TachoSil patch application on a beating heart represents our first choice to achieve hemostasis in LVFWR. This surgical experience, despite the small number of patients treated, shows satisfactory operative and midterm results. The TachoSil patch is very easy to handle and is less stiff than synthetic fabric. Further investigations are needed to establish long-term follow-up after TachoSil patch application.

We thank Pasquale Pellegrino for help in data and picture collection, and Vincenzo Arena for sharing with us the results achieved in his unit.

\section{References}

1. Sakaguchi G, Komiya T, Tamura N, Kobayashi T. Surgical treatment for postinfarction left ventricular free wall rupture. Ann Thorac Surg. 2008;85: 1344-6.

2. Maisano F, Kjaergård HK, Bauernschmitt R, Pavie A, Rábago G, Laskar M, et al TachoSil surgical patch versus conventional haemostatic fleece material for control of bleeding in cardiovascular surgery: a randomised controlled trial. Eur J Cardiothorac Surg. 2009;36:708-14.

3. Muto A, Nishibe T, Kondo Y, Sato M, Yamashita M, Ando M. Sutureless repair with TachoComb sheets for oozing type postinfarction cardiac rupture. Ann Thorac Surg. 2005;79:2143-5.

4. Pocar M, Passolunghi D, Bregasi A, Donatelli F. TachoSil for postinfarction ventricular free wall rupture. Interact Cardiovasc Thorac Surg. 2012;14:866-7. 